Original Research Paper

\title{
Preparation of a Measure of Kinetic Analysis using Artificial Intelligence Methods for Volleyball Coaches
}

\author{
Marwa Ahmed Fadl \\ Department of Training and Kinematics, Faculty of Physical Education for Girls, Alexandria University, Egypt
}

\section{Article history}

Received: 04-04-2020

Revised: 15-04-2020

Accepted: $12-05-2020$

Email: marwa.a.fadl@gmail.com

\begin{abstract}
Coaches need tool codified, modern and fast determine their ability to quantitative analysis using modern techniques to improve the performance and scalability while conducting education and training through the use of analytical skills ByumKaniki modern techniques with coaches some sports selected, as the researcher used the descriptive style screening for suitability and nature of the research, random sample was selected folk 200 coach experience of over 10 years training and tools of data collection is to analyze the references and previous studies, form poil experts and the most important results that can be applied to parameter the period of time not to exceed 15 minutes and that the parameter can be used as a tool had to evaluation and classification of the trainers and the most important recommendations to use a category analysis Byumkaniki skills with modern techniques has trained as a tool to assess and classify trainers and find out their needs to be taken into account when their rehabilitation.
\end{abstract}

Keywords: Kinetic Analysis, Volleyball Coaches, Artificial Intelligence

\section{Introduction}

Invaded modern technology various walks of life were necessary to reach the sports field to live up levels and helps the player and coach on bringing out the best of their abilities normal human through improving and developing training methods, arbitration and also in the manufacture of utilities for Training. The analysis Byumkaniki is the result of information, knowledge and concepts acquired by the analyst, whether a teacher or coach during the preparation of academic and refined during field training and practice the profession, so we must be aware first that there is no final borders stop then and say here we are able to conduct the analysis ideally finished data but we must cultivate our ability to analysis through literacy theories and related sciences to study human motion (mechanics vital learning kinesthetic knowledge growth Education) and put them on the degree of importance and one looking at performance and should take a neutral position them all so you can and one or more of those sciences that attracts performance under analysis the like explains the context is closer to the objective. The scientific knowledge and the independence of research results are applicable play an important role and essential in the design and production of hardware and mathematical tools and innovative search for the best and most suitable raw materials and work to improve the conditions of performance sports to achieve the best sporting achievements with the economy in the energy and effort and time. And determined the arrival of the player to the upper levels by several factors the most important of coach sports, with associated access to those levels is directly related to the ability of the coach to manage the training process, any planning and organization of the training process and the ability to care and guidance and counseling team sports and thus can be considered to coach in terms of that the commander of the technical management process for the team or players in professional sports. We can expect tremendous development in the information technology and personal computers will become cheaper, smaller and more accurate means all symptoms in addition to the availability of databases instant containing a large amount of information in all such purchases after the completion of transactions in banks, reservation for after all the requirements of life will be remote and will use human communication systems because they use computers everywhere in the house and the car and the university and the workplace and the club and public buildings. If the computer is important and essential to our lives future where we need in schools to organize the educational process and the organization of the teaching process in factories and companies in the ministries and different bodies so the athletes when they need it, where we can use it to store information sports and retrieval as 
needed in the ways of modern training and that can determine business training inhalers using computers and take advantage also of the standard equipment for determining physiological variables before, during and after physical activity, as well as analysis of the motor performance of the players, as it is known that the analysis equipment byumkaniki now become equipped with cameras from different angles and with a modern computer. And that most of the research in the field of biomechanics relies solely on sophisticated computers and it thus became necessary to obtain the most accurate results for users. trainer sports is the essential foundation to do the planning and organizing steps Applied training process and directing players during competitions and end sports training operations and its success depends mainly on the availability of properties and attributes and capabilities, knowledge and skills specific to the coach. Coaches and teacher often need to be a logical analysis of the movements so that he can choose the most appropriate means and methods of education and training, to achieve building has this analysis of a study of the variables that explain the performance in the light of past experience and knowledge and information. The requirements of modern technology in the field of modern training is to be able to coach sports to take full advantage of advanced technology in both training devices or technological devices. Which can be used directly in the process of training to upgrade the capabilities of the player's high levels, so he had to keep all developments era and to develop cognitive abilities and gets scientific courses eligible and where the modern technology in the field of sports training variable between day and night, so shall coach, consider the following:

- Attention to educate themselves and participate in the qualifying sessions for the operation of modern devices using the computer as well as identify recent modern techniques in the field of telecommunications

- Paying attention to sports federations and Olympic Committee organized a qualifying sessions which enables the coach to identify all that is new in the world of training and in the field of physical parameters and functional efficiency and psychological area, similar to what happens in the world

- The need to educate coaches and private coaches high levels and national teams to get to know what's new in the world of computer and training in the use of network information (Internet) to familiarize themselves with all that is new in the world

Where developed countries are racing to use new technologies and adapt them in the field of training in order to train more quality to meet the challenges that occur in international sports events and access to advanced centers in the world championships and the Olympics. The mechanical foundations of motor performance is an important element must take coach in the context of an integrated system planning process make the training program more effective and more successful Through observations in the field of educational training was noted that a large number of workers in this field do not use these techniques in spite of its importance, especially after it was known that traditional training methods do not meet the needs of training and do not achieve the desired objectives. And determined the research problem in being an attempt scientific aims to build a parameter of analytical skills byumkaniki quantitative using modern techniques with coaches some sports selected because the belief that the analysis byumkaniki quantitative cost expensive with this saying is at stake after that made computers and spread, making it within the reach of a large segment of individuals and spread with different applications on the computer, including analysis software byumkaniki also believe that this analysis is not only to elite athletes with high performance and this statement also became under study because we are directing novice from the beginning to the sport specific without exercise novice different types of sports and specific operations selection scientific type sports practice the more the level of performance at least the number of errors in the performance and errors by the freshmen be clear and large and easy discovery Yet progress performance amounts to less errors and become difficult observation and discovery and it is necessary to use quantitative analysis byumkaniki with high levels in order to help in the discovery of these errors with the difficulties of belief and first reported in this section researcher recalled that with technological advances I said costs in terms of the spread of laptops (Laptop) and many users. And appeared on the International Network for Information (Internet) analysis software byumkaniki diverse and sometimes free and the spread of digital cameras reduced material cost remains the coach has to deal with these developments trendy that occurred and saves time and effort and be done on a scientific basis, which invited the researcher to build category aims to parameter analysis byumkaniki skills trained in modern techniques in selected sports

\section{Aims}

The research aims to build a Parameter of analysis byumkaniki skills with modern techniques for coaches.

\section{Materials and Methods}

\section{Approach}

The researcher used the descriptive method acting in the survey appropriateness and nature of the research. 
Evidenced by the Table 1 that the approval rate experts on the Parameter category (category analysis skills byumkaniki modern techniques) ranged from $40 \%$ to $100 \%$ has been embraced researcher approval rate $70 \%$ on that is disposed category economy and thus the number of category 5 after Display the experts and be category are (preparation and processing note technical analysis evaluation procedures interference (instructed)).

\section{Preparation of Parameter Phrases}

After selecting the Parameter category, the researcher develop phrases for each category Parameter has been introduced in the initial image experts have been making some adjustments.

\section{Statement Parameter Phrases}

Evidenced by the Table 2 that the total number of phrases category before disposal (64) words were excluded 7 is the lack of access to $70 \%$ of the opinions of experts and the total number of parameter phrases 57.

\section{Reconnaissance Study}

Scoping study is made to the following:

1- How appropriate formulation phrases

Was sure of that by showing the category on coaches

2- Determine the time category:

Time for the application ranged between category (10-15) minutes

3- Get practical difficulties application

Been identified difficulties of application of what the target of the parameter as a tool to help coach before hosted than resulting from the application of all copies of the meter and reached 200 copies

4- Calculation of moderation of distribution of phrases

Table 1: Percentage of expert opinions analysis byumkaniki skills with modern techniques in the appropriate skills (category) $(n=10)$

\begin{tabular}{llcll}
\hline & Skill (category) & Agree & Non agree & Percentage agreement experts' opinions \\
\hline 1 & Note & 9 & 1 & $90 \%$ \\
2 & Preparation and processing & 7 & 3 & $70 \%$ \\
3 & Technical analysis procedures & 10 & - & $100 \%$ \\
4 & Rating & 7 & 3 & $70 \%$ \\
5 & Intervention (instructed) & 8 & 2 & $80 \%$ \\
6 & Contact & 4 & 6 & $40 \%$ \\
\hline
\end{tabular}

Table 2: Statement in expressive terms for each of the parameter category of some sports coaches selected

\begin{tabular}{lclc}
\hline Category & Initial phrases & Phrases excluded & Phrases accepted \\
\hline Preparation and processing & 12 & 3 & 9 \\
Note & 11 & 1 & 10 \\
Technical analysis procedures & 19 & 2 & 17 \\
Rating & 9 & - & 9 \\
Intervention (instructed) & 13 & 1 & 12 \\
Total & 64 & 7 & 57 \\
\hline
\end{tabular}

Table 3: Moderation distribution account statements parameter

\begin{tabular}{llllll}
\hline No. phrase & Skewness & No. phrase & Skewness & No. phrase & Skewness \\
\hline 1 & -0.390 & 21 & -0.498 & 41 & -0.934 \\
2 & -0.244 & 22 & 0.040 & 42 & -0.565 \\
3 & 0.233 & 23 & 0.753 & 43 & -0.619 \\
4 & -1.623 & 24 & -0.828 & 44 & -0.476 \\
5 & -0.657 & 25 & -0.916 & 45 & -0.811 \\
6 & -0.250 & 26 & -0.543 & 46 & -0.973 \\
7 & -0.641 & 27 & -0.588 & 47 & -1.002 \\
8 & -0.433 & 28 & 0.474 & 48 & 0.933 \\
9 & -0.414 & 29 & -0.411 & 49 & 0.927 \\
10 & -0.704 & 30 & -0.704 & 50 & 1.959 \\
11 & -0.464 & 31 & -0.798 & 51 & 0.965 \\
12 & -0.040 & 32 & -1.040 & 52 & 1.569 \\
13 & -0.753 & 33 & -0.753 & 53 & 1.975 \\
14 & -0.828 & 34 & -0.823 & 54 & 1.829 \\
15 & 0.611 & 35 & -1.673 & 55 & -7.729 \\
16 & 0.453 & 36 & -0.543 & 56 & -0.662 \\
17 & -0.588 & 37 & -0.498 & 57 & - \\
18 & -0.476 & 38 & -0.040 & - & - \\
19 & -0.464 & 39 & -0.753 & - & - \\
20 & -0.704 & 40 & -0.288 & - & \\
\hline
\end{tabular}


Evidenced by the Table 3 that the Skewness factor between $( \pm 3)$ This means that the all phrases parameter suitable sample.

5- Scientific transactions of the parameter:

First: Validity

A - arbitrators Validity B - self Validity

The researcher finding transactions validity and reliability of the parameter through the application of the parameter in its final form on (25) coach of the non-core sample and then re-apply it again to extract reliability coefficient was first application 05/03/2012 was the second application 05/18/2012 and the use Researcher Validity arbitrators where was used ten academic experts according to the conditions of experts, was presented parameter them in its principled In light of observation has been making some amendments were presented parameter them again to calculate the coefficient of honesty on the parameter The results showed that all the phrases in the parameter may achieved high transactions ratified by certified internal consistency coefficient was calculated correlation between the degree of each phrase separately and the total score of the parameter and the rationing sample (sample reconnaissance).

\section{A - Validity Arbitrators}

Evidenced by the Table 4 that the proportion of the views of the arbitrators on the occasion of the parameter for the purpose for which it was put $92 \%$.

\section{$B$ - Self Validity}

Self Validity is calculated by the square root of the reliability coefficient and described the parameter 11 and ranged from 0.705 to 0.921 , a function at 0.05 .

\section{C - The Internal Consistency Validity}

Evidenced by the Table 5 that all phrases statistically significant when linked with the total category and the total parameter at the 0.05 level (0.166).

\section{Second: Reliability}

A - Reliability account Test-Retest period of 15 days from the first application.

Evidenced by the Table 6 that the correlation coefficient of the main category parameter and ranged from 0.705 to 0.921 , a function at the level of 0.05

B - the expense of Reliability

A factor Alpha Cronbakh way where coefficient has been found Alpha Cronbakh category.

Table 4: Wanted arbitrators in the appropriate parameter for the purpose for which it was put $(n=10)$

\begin{tabular}{|c|c|c|c|}
\hline Statement & Well suited (5 marks) & $\begin{array}{l}\text { Somewhat appropriate } \\
\text { (3 degrees) }\end{array}$ & $\begin{array}{l}\text { Inappropriate } \\
\text { (1 degree) }\end{array}$ \\
\hline Number of views arbitrators & 8 & 2 & - \\
\hline Total & 46 & & \\
\hline Percentage & $92 \%$ & & \\
\hline
\end{tabular}

\begin{tabular}{|c|c|c|c|c|c|c|c|c|c|c|c|c|c|c|}
\hline $\begin{array}{l}\text { No. phrase } \\
\text { first } \\
\text { category }\end{array}$ & $\begin{array}{l}\text { Consistency } \\
\text { with the } \\
\text { category }\end{array}$ & $\begin{array}{l}\text { Consistency } \\
\text { with the total } \\
\text { category }\end{array}$ & $\begin{array}{l}\text { No. phrase } \\
\text { second } \\
\text { category }\end{array}$ & $\begin{array}{l}\text { Consistency } \\
\text { with the } \\
\text { category }\end{array}$ & $\begin{array}{l}\text { Consistency } \\
\text { with the total } \\
\text { category }\end{array}$ & $\begin{array}{l}\text { No. phrase } \\
\text { Third } \\
\text { category }\end{array}$ & $\begin{array}{l}\text { Consistency } \\
\text { with the } \\
\text { category }\end{array}$ & $\begin{array}{l}\text { Consistency } \\
\text { with the total } \\
\text { category }\end{array}$ & $\begin{array}{l}\text { No. phrase } \\
\text { fourth } \\
\text { category }\end{array}$ & $\begin{array}{l}\text { Consistency } \\
\text { with the } \\
\text { category }\end{array}$ & $\begin{array}{l}\text { Consistency } \\
\text { with the total } \\
\text { category }\end{array}$ & $\begin{array}{l}\text { No. phrase } \\
\text { fifth } \\
\text { category }\end{array}$ & $\begin{array}{l}\text { Consistency } \\
\text { with the } \\
\text { category }\end{array}$ & $\begin{array}{l}\text { Consistency } \\
\text { with the total } \\
\text { category }\end{array}$ \\
\hline 1 & 0.972 & 0.956 & 1 & 0.860 & 0.846 & 1 & 0.866 & 0.846 & 1 & 0.742 & 0.742 & 1 & 0.720 & 0.724 \\
\hline 3 & 0.898 & 0.897 & 3 & 0.832 & 0.829 & 3 & 0.841 & 0.829 & 3 & 0.869 & 0.866 & 3 & 0.859 & 0.866 \\
\hline 4 & 0.905 & 0.706 & 4 & 0.862 & 0.866 & 4 & 0.868 & 0.866 & 4 & 0.874 & 0.877 & 4 & 0.890 & 0.877 \\
\hline 5 & 0.906 & 0.897 & 5 & 0.871 & 0.877 & 5 & 0.871 & 0.877 & 5 & 0.835 & 0.836 & 5 & 0.855 & 0.836 \\
\hline 6 & 0.863 & 0.863 & 6 & 0.825 & 0.836 & 6 & 0.827 & 0.836 & 6 & 0.862 & 0.780 & 6 & 0.880 & 0.880 \\
\hline 7 & 0.902 & 0.906 & 7 & 0.866 & 0.871 & 7 & 0.872 & 0.871 & 7 & 0.832 & 0.759 & 7 & 0.825 & 0.815 \\
\hline \multirow[t]{9}{*}{9} & 0.825 & 0.676 & 9 & 0.788 & 0.704 & 9 & 0.765 & 0.784 & 9 & 0.911 & 0.675 & 9 & 0.899 & 0.915 \\
\hline & & & 10 & 0.921 & 0.915 & 10 & 0.915 & 0.915 & & & & 10 & 0.749 & 0.749 \\
\hline & & & & & & 11 & 0.729 & 0.846 & & & & 11 & 0.675 & 0.675 \\
\hline & & & & & & 12 & 0.616 & 0.727 & & & & 12 & 0.659 & 0.966 \\
\hline & & & & & & 13 & 0.720 & 0.616 & & & & & & \\
\hline & & & & & & 14 & 0.614 & 0.720 & & & & & & \\
\hline & & & & & & 15 & 0.763 & 0.684 & & & & & & \\
\hline & & & & & & 16 & 0.665 & 0.763 & & & & & & \\
\hline & & & & & & 17 & 0.735 & 0.665 & & & & & & \\
\hline
\end{tabular}

Table 6: Correlation coefficients between the first and second application

\begin{tabular}{|c|c|c|c|c|c|c|c|}
\hline & \multirow[b]{2}{*}{ Skill (category) } & \multicolumn{2}{|c|}{ First application } & \multicolumn{2}{|c|}{ Second application } & \multirow[b]{2}{*}{ Value (R) } & \multirow[b]{2}{*}{ Self validity } \\
\hline & & Mean & $\mathrm{SD} \pm$ & Mean & $\mathrm{SD} \pm$ & & \\
\hline 1 & Preparation and processing & 38 & 7.762 & 39 & 6.968 & 0.921 & 0.959 \\
\hline 2 & Note & 42.580 & 8.088 & 43.270 & 7.925 & 0.909 & 0.953 \\
\hline 3 & Technical analysis procedures & 72.45 & 13.731 & 74.290 & 13.069 & 0.865 & 0.930 \\
\hline 4 & Rating & 38.270 & 7.276 & 40.320 & 6.590 & 0.705 & 0.839 \\
\hline 5 & Intervention (instructed) & 51.210 & 9.750 & 53.430 & 8.850 & 0.735 & 0.857 \\
\hline
\end{tabular}


Table 7: Reliability Form questionnaire in Alpha Cronbakh manner

\begin{tabular}{lllr}
\hline Category & Alpha & Mean & \multicolumn{1}{c}{ SD \pm} \\
\hline Preparation and processing & 0.976 & 38.00 & 7.762 \\
Note & 0.974 & 42.580 & 8.088 \\
Technical analysis procedures & 0.993 & 72.450 & 13.731 \\
Rating & 0.978 & 38.270 & 7.276 \\
Intervention (instructed) & 0.971 & 51.210 & 9.750 \\
Total & 0.982 & & \\
\hline
\end{tabular}

Clear from Table 7 that the value of alpha 0.982 indicating Reliability highly questionnaire.

\section{Statistical Treatments}

All statistical treatments of the data have been carried out using computer packages of statistical programs where Spss Statistical analyzes included the following: arithmetic mean, standard deviation, Skewness, Alpha Cronbakh, correlation coefficient, percentage, Coefficient of variation.

\section{Results and Discussion}

Clear from Tables 1 to 7 , the parameter became finalized and that honest and consistent in the light of the outcome of the results and according to expert opinions to the Table 1. And so that category preparation and processing, the percentage of agreement expert opinions $70 \%$ and the category of observation was by the consent of experts by $90 \%$ The category analysis procedures technical was the consensus of experts attic 100\% and then comes after a centerpiece of the assessment rate was approved experts attic $70 \%$ and then the category of intervention, which was approved by experts $80 \%$

The skill preparation and processing got $70 \%$ of the approval rate experts because it is considered the starting point, which begins its analysis byumkaniki then the skill of observation and got $90 \%$ due high note of the diversity of use as a tool of data collection with a variety intended to have been used in the assessment tool or infinite repetition of skills (Khater, 1985; Ala Elddin, 2007; Awad Mohammed, 1991; Michael, 1987; Morse, 1988; Burstein, 1988; Hay, 1985). Then skilled technical procedures for analysis due to its importance in the precise stages of movement and application characteristics, allowing the development of performance. Then came the focus and skill evaluation and then the center of intervention (direct instructions) This is a logical parameter would have to come after the end of the assessment and stand on the weaknesses performance and intended use of nutrition retro apostate (Salem, 1990; Laurak, 1989). With regard to skill or category of communication does not mean not achieve the required percentage to totally indispensable because it is implicitly traffic especially when you make a note (Husam Eldin et al., 2006; Knudson, 1997;
2002). As can be seen from Table 3 The torsion coefficient ranged between $(+3)$ and this means that the all phrases formula suitable sample due to the procedures followed in the Tables of 3-7 and the relative importance of phrases axes parameter.

As is clear from Table 4 that ratified the arbitrators reached $92 \%$. As shown in Table 5 self-honesty through the square root of reliability coefficient, a D at 0.05 As shown in Table 6 come standard fixed in a test application and reapply a period of 15 days from the first application where the correlation coefficient for the category parameter ranging from 0.705-0.921. As shown in Table 7 account Reliability Alpha Cronbach coefficient which shows the degree of Reliability of the category where the total number of standard phrases 57 . By 9 phrases to the category of preparation and motivation 10 statements to the category of observation and 17 words to the of the category technical procedures for analysis and 9 phrases to focus assessment and 12 words to the category of intervention (Instructed).

\section{Conclusion}

The Researcher Concludes the Following:

1- Subordination standard for transactions of scientific validity and reliability can be used as a tool had to evaluation and classification of trainers generally

2- Can be applied to measure the period of time between 10-15 $\mathrm{min}$

3- Can be measured kinetic analysis techniques with modern sports coaches selected through skills (note kinetic analysis - Calendar - therapeutic intervention)

\section{Recommendation}

The researcher recommends the following:

1- Attention kinetic analysis with modern techniques within the decisions of the study physical education faculties and training courses and refinement of the selected sports coaches

2- Building scale kinetic analysis skills with modern techniques of sports coaches selected as a tool to assess and classify the teacher and find out their needs to be taken into account when rehabilitation

\section{Ethics}

1- Attention kinetic analysis with modern techniques within the decisions of the study physical education faculties and training courses and refinement of the selected sports coaches

2- Building scale kinetic analysis skills with modern techniques of sports coaches selected as a tool to 
assess and classify the teacher and find out their needs to be taken into account when rehabilitation

\section{References}

Abdel Rahman, N.A., 2004. Sports training system. Dar Al-Fikr Al-Araby, Cairo.

Abdul Latif, M.S., 2000. Choto of Karate. Cairo.

Ala Elddin, J., 2007. Metrological basis to evaluate the level of physical performance and skill and tactical for athletes Alexandria.

Aly, B.M., 2003. The design of the electronic control modify arbitration juridical system and the extent of Contribution to the results of games Alcolmtah. Minia University.

Awad Mohammed, A., 1991. A study of the evolution of the Allagaf the children pre-school. College Physical Education Alex Boys.

Brika, M.J., 2010. Charity Ibrahim diabetes: Qualitative analysis. Facility Knowledge Alexandria.

Burstein, D., 1988. The effect of using video imagery fusion in learning swimming skills. Dissertat. Abs. Int.

Hay, J.G., 1985. The Biomechanics of Sports Techniques. 3rd Edn., Prentice Hall, Englewood Cliffs, NH., ISBN-10: 0130783048, pp: 539.

Husam Eldin, T.H., 1994. The scientific principles of diagnosis of movement. Dar Al-Fikr Al-Araby.
Husam Eldin, T.H., T.F. Abdul Samad and M.F. Abdul Shakoor, 2006. Qualitative analysis. World Publishing House and Distribution.

Ismail Alhawe, Y.E., 2002. Sports coach between traditional methods and modern technology in the field of training. The Arab Center for Publishing, Cairo.

Keith, A.J., 1993. How coaches teach the physical education.

Khater, A.M., 1985. An analytical study of the effectiveness of motor performance of the players Kuwaiti soccer team During science Cup 1982. J. Stud. Res. University Helwan.

Knudson, D.V., 1997. Qualitative analysis of human movement. Human Kinetic, USA.

Knudson, D.V., 2002. Qualitative analysis of human movement. Human Kinetic, USA.

Laurak, E., 1989. The effect of video taped feed back on the performance of tennis serve. J. Motor Behav.

Michael, F.G., 1987. Kinetic analysis of the evolution of skill throwing the children of pre-School Master of Physical Education College, Alexandria.

Morse, K.S., 1988. Evaluating the effectiveness of performance skills of handball players during the game. Proceedings of the Magazine Scientific Conference Breeding Sports Minya, (BSM' 88).

Salem, M., 1990. Sports equipment technology Alexandria. 